\title{
The Dynamics of Public Participation in the Integrated Management of Natural Resource and Environment: A Case Study of Ban Pa Sak Ngam, Luang Nuea Sub-district, Doi Saket District Chiang Mai Province
}

\author{
Winit Pharcharuen ${ }^{\mathrm{a}}$ \\ ${ }^{\text {a }}$ School of Administrative Studies, Maejo University, Thailand \\ Email: ${ }^{a}$ winit.phacharuen@gmail.com
}

Article History: Received: 10 January 2021; Revised: 12 February 2021; Accepted: 27 March 2021; Published online: 20 April 2021

\begin{abstract}
The purpose of this study was to 1) 1) To study the social context, Politic and Governance, Culture and Economy based on participatory development of the public sector in managing natural resources and the environment 2) Study the dynamics of development and adaptation process for the restoration of community natural resources and environment. 3) To propose guideline and mechanism for management of sustainable integration of natural resources and environment. This research is qualitative and participatory workshop research, which lead to the strengthening of communities and agencies in the area for management of sustainable integration of natural resources and environment. In terms of the social context, they were like family, they social structure consist of both vertical and horizontal. In terms of politics and governance, it was decentralized by dividing the community administration into categories. There are common rules and regulations of the village. In terms of community culture, there are cultures, traditions, beliefs, and rituals that are inherited from their ancestors. And finally, in terms of the community's economy, there are abundant natural resources, which serves as a capital cost of production, to support the community's economy, the use of local intellects as a base for strengthening the community. These includes local intellects, learning of the community leaders and knowledge transfer, conservation of natural resources and adaptation to change The results of this research showed that the dynamic process of development and adaptation with the participation of the people in the management of natural resources and environment can be divided into 4 categories as follows: 1) Settlement Stage, 2) Franchise and transition stage 3) Development and adaptation stage and 4) Current Stage. However, the overall picture of changes in natural resources and environment result in critical damages on the community's ecosystem, hitherto, the community benefit from the ecosystem and they are also affected by these damages. Therefore, they are being pressurized by the government to suppress, prevent and conserve the community's forest. Therefore, the community's learning process became aware of the joint efforts to restore, conserve, preserve, protect and benefit from biodiversity without affecting livelihoods and environments. The Natural Resources and Environmental fund of Ban Pa Sak Ngam Community is a foundation for maintaining a sufficiently good quality of life. The extensive forest area is a source of abundant biodiversity production. Forest management in various forms, as well as lessons and knowledge gained by the community used to drive all aspects of development work. Therefore, it was discovered the approach and mechanism for integrated natural resource management are 1. Community development based on natural resources and environment 2. Development as a center for environmental studies 3 . Development as a center for the transfer and teaching of the King's Philosophy. 4. Development as a health development center based on environmental education and to develop as a center to support learning and research processes of educational institutions.
\end{abstract}

Keywords: Dynamics of Development Process, Participation of the Public Sector, Adaptation and Restoration of Natural Resources and Environment.

\section{Introduction}

In the past, the Thai government has focused on only one part in accelerating economic development, causing the situation of natural resources and the environment in Thailand to change rapidly in terms of soil, water, forest, and wildlife resources. All these things are important factors in the development of the country, and they play a vital role in poverty eradication. However, we cannot deny the fact that Economic development inevitably harms natural resources in exchange for material prosperity and the well-being of people in general [1]. According to the report on the situation of Thailand's natural resources and environment, it was discovered that the forest area across the country in 2018 - 2019 amounted to $102,484,072.71$ rai, or 31.68 per cent of the country, in 2017-2018 was there a decrease in the amount of 4,229.48 rai [2]. The trend on natural resource and environment situation shows that there is change due to the driving force of the whole country both within and outside that has occurred within past years. However, they result in both direct and indirect effect to environmental activities of human making the overall quality of natural resources within the country to deteriorated including an imbalance in the ecosystem.

However, problems arising from the struggle for natural resources and the environment persist due to change and continuous increase in population and solving the problem in a structural nature from government policy (Top-Down 
Approach), the said approach could not solve the problem to be successful, as cited by Natthawat Sunthornwaritichot, who said that the main cause of the environmental problem is that, people lack participation, they lack conscience to take responsibility, they mainly think of personal benefits, they lack discipline and lastly, the people believe that preserving and solving environmental problems is the duty of the government and not them. Therefore, participation is the key foundation to create awareness on the conservation of natural resources and environment [3].

The northern region, in the past, was fertile in terms of natural resources and the environment. Forest areas, mainly at the northern are tropical forest moist in the mountains and is a source of fine teak with foreign private companies coming to exploit the forests in Thailand. Since the government introduced the $1^{\text {st }}-9^{\text {th }}$ National Economic and Social Development Plan, there have been policies to develop the economy, quick development of the industrial sector and commercial use of forest land by the government, giving forest concessions to foreign logging companies. Making the foreign logging process more open. However, these concessionaire cuts the entrance to the area. The company established itself as the conqueror of the forest. We can find them in 2 areas: the area where the community lived before concession companies are required to coincide with the power of the local community. They have to pay for their influencers in the community for logging. Because logging conflicts with the occupation and interests of the villagers. The logging companies employ some community workers as loggers and bring in outside workers. However, when these companies moved, they only moved their workers out as well, only some of them could not move with them because they have a house here already. The area where there was no community before the logging concession, the company will bring outside workers to cut large and valuable timber and move them to other areas [4] indicating that the northern area expanded both its economic and social aspects with the necessity of relying on various natural resources that have existed and fertile to be used as a fundamental factor in production, resulting in quick deterioration of those natural resources, without systematic management plan to restore them to their original state. However, they are still lacking to think about the future effect as a result, those natural resources deteriorate, changing its factor to contribute and now become a limitation to development.

Although the problems in forest management in the past seems to be a failure of the government, the people within the area also contribute to the deterioration of the health of the forest. This may be due to a lack of management knowledge or based on finding profit for themselves and their associates in illegal logging, in exchange for the huge sums of money that could be obtained, or combination of people in power both within the outside. However, these problems may come from the unemployed villagers or those who lack their land, making them use it as a channel to get and exploit benefits from the natural resources, including the lack of tools, equipment and budget to maintain the forest in the area.

From the development stream of capitalism that has changed the consumption behaviour or the reckless use of resources, lack of consciousness, selfish use of natural resources, and not being of benefit to the majority of the people, resulting in the gradual deterioration of natural resources. Ban Pa Sak Ngam, Luang Nuea Sub-district, Doi Saket District Chiang Mai Province, originally has always been fertile with tremendous natural resources such as a source of water, streams, wildlife, and abundant diversity from the forest, and it is also a good source of teak wood. Later, there were foreign private companies that came to engage in logging activities since 1960 based on the forest concession issued by the government. The villagers turned to contract for logging and plantation for logging companies and the forestry industry in 1984, they were hired to survey the trees, take care of the trees, mark the trees, number the tress, cut and maintain them [5] For this reason, the people in the community learn to cut wood, handle equipment and, there was a reversal from the people, who had been hired to make the villagers started to turn to be a wood manufacturer and sell by themselves. They began the illegal logging and divided the area together for processing timber sold alongside with the capitalist. Also, there are supports from the capitalists in terms of both tools and money used for wood processing, After some time, those who became successful now become subject of imitation by other villagers. They start buying chainsaw into their homes for more logging, cutting, and processing of woods expand continuously, up to the extent they started cutting the forest trees, which later results in forest degradation. Thus, causing the flowing water, which crosses the creek to dry up and cannot be used for the cultivation of rice and community consumption water became scarce like never before. The forests, which was once a place for a wide variety of wildlife began to reduce. The community have to pay the price of the advantages taken away by the people outside the community, they took away the abundance of natural resources, it became a trigger point and the source of the problem. The condition of the forest was destroyed and there was the movement of government policies and investors from outside of the community.

In 1982, His Majesty King Bhumibol Adulyadej Rama 9 as part of the royal initiative, establish a project called Huai Hong Khrai Royal Development Study Center, and in 1992 they established a project to Develop Khun Mae Kuang Forest as another part of the royal initiatives covering the forest area of Mae Kuang at 345,000 hectares. Ban Pa Sak Ngam, therefore, became the first community project that was solved urgently, because soldiers were sent into the village to help stop Illegal logging and their selling. Moreover, Ban Pa Sak Ngam was the mainstream of water consumption and utilization, which as a result see government agencies and projects sent into the village to help with the restoration and support of the area, by making the community aware and focus on how to solve arising problems to make the forest fertile again before deforestation. Therefore, organized a forum for brainstorming and seeking suggestions that will help conserve and develop forest regeneration and cross creeks, this was done with the integration 
and creation of "The conservation and development group of Pa Sak Ngam" For the past 10 years now, the community had been awarded various certification on the restoring and conserving of the forest according to the royal initiative. This serves as a reminder of how the community had become successful and now a learning centre for other interested communities. [6]

From the current situation, the community is now facing a powerful capitalism problem as a result, the relationship between the community and the natural resource base has changed. Although the community knew what they will lose, they have no other choice. Because of the need to struggle to survive the situation. Therefore, this study aims to find answers to the issues of the context and development of natural resource management and community adaptation process of community rehabilitation resources under dynamic and high complexity. By using Ban Pa Sak Ngam community, Luang Nuea Sub-district, Doi Saket District, Chiang Mai Province as a case study, because Ban Pa Sak Ngam is a strong community that has long been in the good management of the natural resource. Which will be useful in joint learning to be able to link and expand the pattern of forest recovery approaches to other areas with similar contexts.

\section{Research Objectives}

The objectives of this research article were 1) to study the social context, Politic and Governance, Culture and Economy based on participatory development of the public sector in managing natural resources and the environment. 2) to study the development dynamics and adaptation processes for the restoration of natural resources and the environment of the community, and 3) to suggest guidance and mechanisms for sustainable integrated natural resources and environmental management.

\section{Research Methods}

This research was carried out with a qualitative method with the following details:

A. Collection of data: Data were retrieved through document research, this was a collection and analysis of qualitative data from relevant research, academic papers, related journals, related government textbooks, field research, organizational study, and villagers, in-depth interviews. The key informant's interview was carried out using a questionnaire and observation to collect their data both those involve and those not involved in the community organization activity management, which include attending meetings or events carried out by the villagers. etc.

B. Research tools: The instrument used in this study include: 1) Specification of Key Informant as a group of people involved with the conservation of forest trees in the community such as Community leaders, religious leader, professional experts, scholars, and relevant authorities, including villagers at a total of 25 people. 2) Focused group: Interview was used as a model of brainstorming session using Appreciation Influence Control, Brainstorming, Mind mapping, to achieve clarity on various issues with the people in the community. 3) Non- Participant Observation: this was done using a checklist to study the behaviour and attitudes of the people in the village from engaging in various activities 4) Observation this is a technique of gathering research data, by keep watching or studying the various phenomenon that is happening and 5) Participatory meetings: this was done by brainstorming in other to understand the problems, needs of the community and their potential in various sectors.

C. Data analysis: Considered issue were classified into four modern eras, 1) Settlement era, settlers established or before the concession period 2) Franchise and transition era, 3) Development and adaptation era and 4) Current era. By understanding the interaction between community activities, to analyze the link between the human ecosystem and the physical ecosystem in the holistic area, as well as the adaptation of the community and related agencies when confronted with problems and find appropriate solutions. The analysis of this data lies on two key concepts:

(1) The concept of a network: is a key concept and is used to describe the movement from group to network to drive the development process or to change things in the operational process to achieve network development. The networks are as follows: 1) raising awareness is the fusion of ideas, knowledge, experiences through a continuous learning process; 2) creating common ideologies through learning and changing experiences, problems, and obstacles. It is a database that compiles the goals and objectives or the common ideology of the community leaders. 3) Network formation is the determination of the structure and strategy for implementation. Brainstorming ideas to disseminate to groups at the community level know the guidelines 4) Developing capacity through exchanging knowledge, brainstorming network operations to strengthen communities and networks. 5) Planning covers 3 issues: care, protection. Rehabilitation Development for better quality and utilization 6) Promotion and implementation to drive action activities 7) Lesson summary and evaluation. To improve, modify or develop network projects/activities [7] .

(2) The concept of natural resource management consists of five main frameworks: 1) a view of the production system and natural resource management in the context of economic, political, and ecological structure changes; 2) cultural context. The relationship between human and nature is holistic, 3) the view of the resource management system as part of the shared ownership system of the community, 4) the view of the community resource management system as 
a social movement, and 5) the context of the community ownership system. Rural development and conservation and restoration [8].

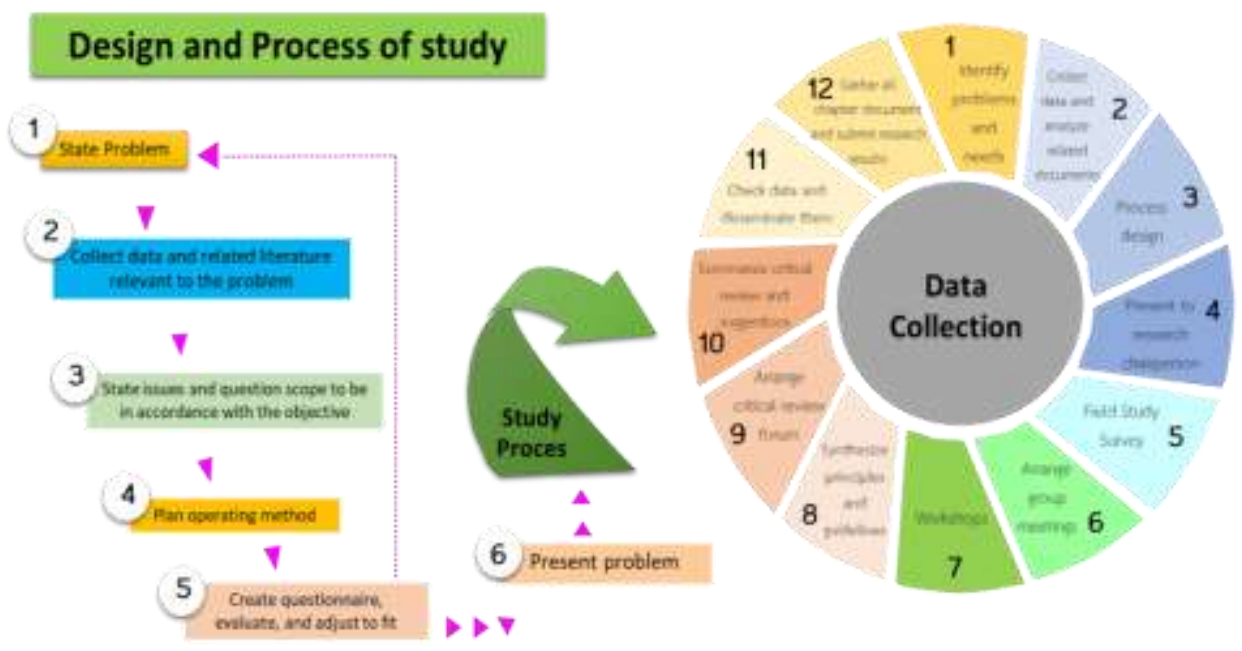

Figure 1 Study design and process

\section{Research Results}

1) According to the study, after studying the social context, Politics and governance, Culture and economy, based on the people's participation in the management of natural resources and environment. The result found that the community had a social relationship in form of family cycle, they had both vertical and horizontal social structure, group members are organized by setting common objectives or goals for problem solving or community development. Group management is organized in form of committee structure, they divide their duties and responsibilities together, there is learning and knowledge transfer, they help each other. As well as building networks both within and outside the community to create power in joint activities. In terms of politics and government, there was decentralized division of community administration in a form of unit head, the unit head is responsible for 10-15 houses, to assist in the administration and coordination of activities. The village headman acts as a coordinator between the government and the people. This is an important mechanism that allow and help to achieve integration, brainstorming, and exchange of knowledge. Hence, making it democratic political mechanism at the local level, in determining the direction of village development and mobilizing all contributions to assist in the administration and coordination of community activities, with the community rules and regulations as the basis for mutual peace. In terms of culture, this research found that culture, traditions, beliefs and rituals were considered as social capital of the community, it is an important tool and an anchor for the people of the community. Passed by their ancestors from generations to generations. Through relationships as a network, Neighbors and activity groups. Therefore, there are always joint activities in the community that are developed towards solving community problems, making the community self-reliant with dignity. In terms of the community's economy, the result of the research found that, the sufficiency economy concept was applied within the community. They practice Integrated agriculture, this allow them to gather member group, and is often empowered at the community level. The community livelihood was by organizing groups or organizations for production, distribution, fundraising, savings, to serve as a financial institution of the community, they have and engage in activities that help reduce cost, increase income, which help promote the economy of the community and organize the market in the community. For the exchange of products between communities and communities and between the producer and the consumer through the empowerment of the community at the individual and community level, which is an important mechanism, which help strengthen and create sustainability of a learning community.

2) Development dynamics and adaptation processes for the restoration of natural resources and environment of the community. The evolution of the use of natural resources and environment of Ban Pa Sak Ngam community at each period has it's own distinct characteristics and can be classified according to time frame into 4 main eras which are:

Settlement era: It is a time when the environment and natural resources are fertile, good soil, water flowing all year, abundant wildlife. Forest products are also abundant, smaller communities are making use of resources as dependence on family and community recruitment processes. The forest is treated with respect and there are rules of care that are consistent with traditional and traditional lifestyles, therefore the economic system is closed. Production and consumption are sustenance only.

The era of concessions and transitions: It was a time that communities began to interact and learn more from outside. Both from the forest concession, that the private sector has entered into the logging process, forest land leasing, by utilizing natural resources and earning income until creating a full-fledged illegal log trade, together with the 
cooperation of the insiders and outside in the community. Making them neglect agriculture, leaving the area to be desolate and selling them to private investors. Natural resources are viewed only as a source of income. Thus, natural resources were fully used and eventually degraded.

The development and adaptation: Since 1952, King Bhumibol Adulyadej King Rama IX began to visit people in every region of the country. His Majesty's wish to acknowledge the troubles and needs of the majority of the people who work in agriculture, firstly he visited the people in the northern region in 1958 and a royal initiative began, which emphasizes the importance of natural resources and environment. The royal initiative project made some highlights on the importance of agriculture natural resources and environment, which was the base of the people to be in balance. His work in the area and the establishment of a royal project in the Khun Mae Kuang National Reserved Forest from 19761992 from the royal initiative was to build the Mae Kuang Udomthara dam, Huai Hong Khrai Royal Development Study Center, and the Khun Mae Kuang Forest Development Project. However, these royal initiatives cause different activities that damage the forest area. Therefore, people in Ban Pa Sak Ngam community have to adjust their livelihoods and enter the development process of the government, learn to develop a variety of careers. Including taking part in restoring, maintaining, and preserving natural resources and the environment to be fertile as before.

Modern era: Throughout the development period, adapt and co-operate activities on the conservation of natural resources and the environment. Continuously improve the quality of life There are all sectors to support the development. Including government agencies, private institutions, educational institutions, and community networks across the country. Communities, therefore, play various roles in natural resource management. Both as a learner, operator, coordinator, and broadcaster. As well as being a developer from all sectors according to many government policies or projects.

From the change of natural resources in each of the above periods, it pointed out, that under the situation of natural resource loss, it causes a serious impact on the ecosystem of the community, who are the beneficial and user, including being affected directly under pressure from the government to suppress and protect forest areas. Therefore, awareness and joint efforts have been made to protect and restore natural resources, with the details as follows:

a) Lesson review: Analyze and modify thinking methods, after being pressured by the government, both entering and setting up a unit of defense and suppression of forests in the area and also setting up development from government agencies. This allows the community to get to know and learn with the scholars, who are introduced into the community development process starting from self-learning, adopt new thinking method for development, learn and understand the principles of life. That must have natural resources as a base for their livelihoods and improve the quality of their life.

b) setting options and planning the community: The community analyzes its potential and specify operation guidelines as follows: 1) agricultural areas: carry out activities for cultivating a variety of agricultural products free from chemicals 2) Forest areas near homes: plant three types of wood with four benefits such as rattan, bamboo, and local wood. 3) Watershed forests: Carry out rehabilitation and maintenance activities, including building dams, upstream, make a line to prevent forest fires and extinguish forest fires. 4) Management of groups in the community such as conservation and development groups, Agriculture for a life group, Occupation group, they operate by carrying out rules, regulations, and participation in various activities, in which, in the operation of each activity, government agency, academician in the organization unit, that continuously support the learning process in the community.

c) operating under wisdom and participation: Community leaders act on behalf of various groups, they act as Public relations officer in inviting other people and they also lead in that mission, resulting in various activities. Including the development of soil resource quality, forest water, career development, additional careers from conservation. Involving all sectors to promote and support in terms of materials, equipment, budget, knowledge, and others until they can become a learning centre and exchange experiences with other areas and people are coming for an excursion.

d) Networking and Learning Power: The learning network allows the community to develop their potential. share experiences and taught lessons from various networks in Mae Kuang River Basin. The River basins in the northern and all regions of Thailand use this development and continue them further into activities their various community. As well as building morale and encouragement for the community leaders to ignite the drive and strength to work harder in Ban $\mathrm{Pa}$ Sak Ngam community. There are also exchange and strength reinforcement on a large scale.

3) Guideline and Mechanism for Management of Sustainable Integration of Natural Resources and Environment.

According to the study from the representative in the community group, and the analyzes of data from the community referendum. We were able to design guidelines and mechanisms for the management of sustainable integration of natural resources and environment as follows:

a) Community development based on natural resources and environment: It is to make the best use of natural resources and biodiversity without affecting the environment. By carrying out conservation and rehabilitation activities to make natural resources abundant, including building dams creating a wet forest, fire prevention and suppression to inspect, patrol, prevent, suppress, etc., and support groups to manage and utilize resources in the community, such as natural fertilizer production, agroforestry group, forest seedling group, etc. 
b) Center for Environmental Studies: This is a method knowledge dissemination and creating awareness of conservation to acts as a natural classroom and thereby, creating a working group consisting of community leaders, Educational institution different networks, to jointly manage the database system. Create a process for developing environmental education courses and support the learning of environmental education for learners at different levels appropriately.

c) The King's Philosophy Exchange Center: This is a way of spreading and dissemination of the King's philosophy in terms of natural resource conservation and improving the quality of life, by creating a curriculum for disseminating and expanding the concept of the theory in collaboration with the Mae Kuang River Basin Conservation Organization and Network, named as The Sustainable Development Model Course in Watershed, Wet forest, fire protection lines, etc., thereby using the community area as a learning centre for both theory and practice also extending the learning process to networks in other areas.

d) Health development center based on the natural environment: It is to promote and support the development of quality of life and health. By designing activities aimed at changing health behaviours such as nature walks, birdwatching, consumption of food and herbal drinks, and organizing learning about community lifestyles and natural systems in the homestay to support the service of the elderly society.

e) Center to support learning and research processes: This is to coordinate, cooperate and support learning and research processes for educational institutions by using the learning resources in the community, use of media in teaching and learning following the university course. For the integration of education and learners can apply the knowledge learned in the university to benefit the community and society, therefore creating a piece of new knowledge and innovations through the research work of lecturers and faculty members.

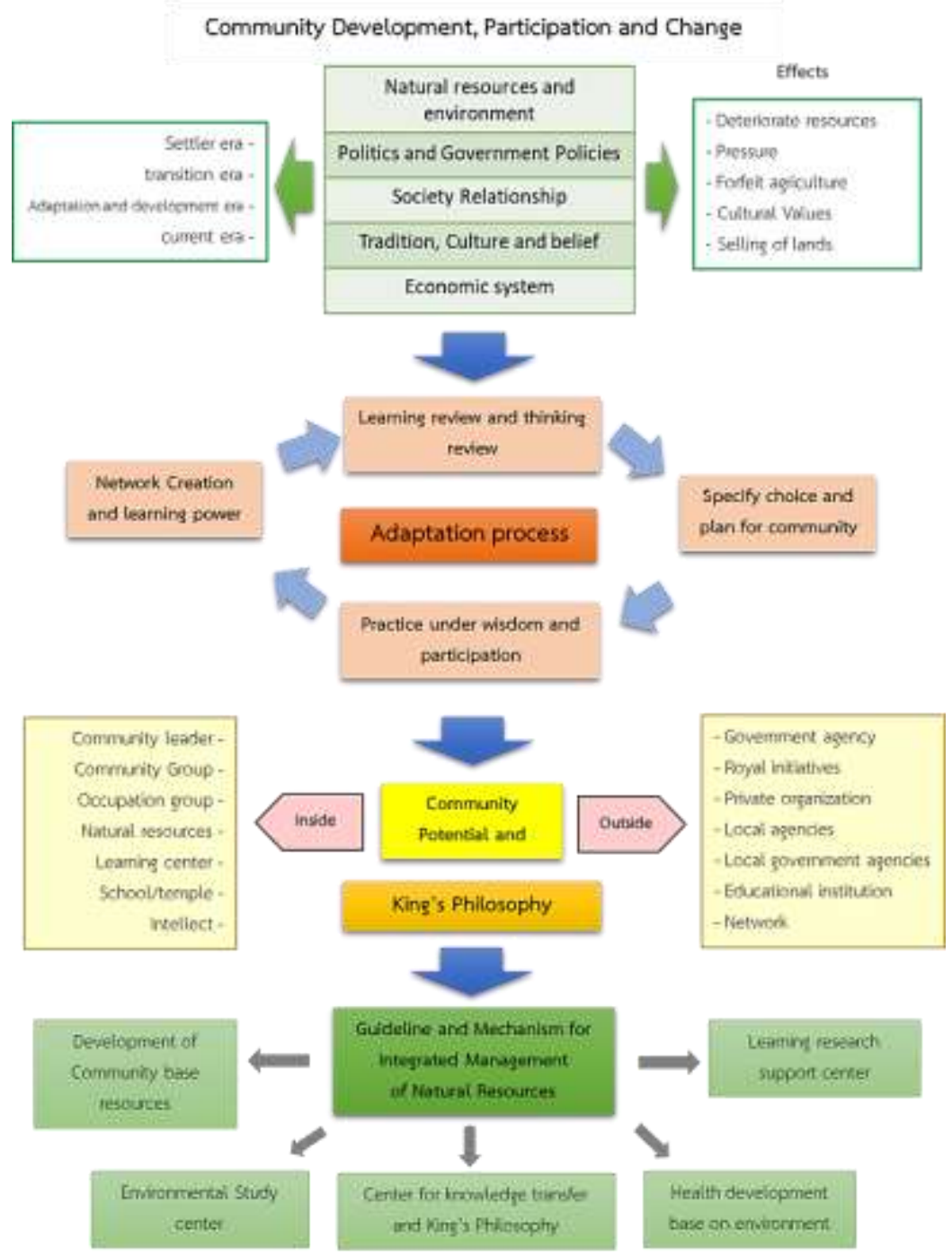

Figure 2: Dynamic public sector participation in sustainable integrated natural resources and environmental Management.

\section{Suggestion}

Based on the study the researcher has the following suggestion and recommendation. 


\subsection{Policy Recommendation}

Current development policies affect the community's adaptive learning process, especially in terms of interaction with the management of the community relationship with a natural resource if there is some kind of policy power, which use rules and regulations, that do not prioritize the basic lifestyle value, tradition, culture, wisdom, and implementation of the policy. Taking advantage from the outside May cause conflict in the community. The lesson learnt by Ban Pa Sak Ngam community, such as forest concessions or setting up development policies that focus on economic benefits. Thus, the resource management relationship model will also focus heavily on taking advantage. Privatize every resource for income will be essential. Thus, expedite the mobilization for the community to use them regardless of the impact that might occur.

Adaptation development of Ban Pasak Ngam community will reflect in the policy of giving importance to the learning of the community. This community is a subject to excessive tightening, control or enforcement of government regulations. Changes for adaptation development to be able to live in the area in a supportive relationship with natural resources and community environment under learning conditions of being in harmony with the sustainable lifestyle of the community environment, however, the community - centred policy in the development process and participation of the community Hence, becoming a guideline as a development model according to the royal initiative of His Majesty King Bhumibol Rama IX "Development based on geospatial Society". Therefore, it should be an important guideline for leading to policy formulation for the management of forest resources with the participation of the community.

\subsection{Suggestion from Workshop}

The results of this research study, developers, researchers and staff in the agency both public and private organizations can be used to understand the lifestyles relationship of local communities that are dependent on natural resources and the environment. This will be useful in developing the process of working with the community in the field of production, conservation and development of natural resources and the environment following the community. The following are the thing to be held on high importance 1) in community development, we should emphasize the value system of knowledge and traditional wisdom and be consistent with community potential this will make the community stronger, and capable of being self-reliant 2) The development of the community learning process should be promoted by supporting the creation of a learning platform. Regularly stimulating or presenting new knowledge that will benefit communities in the management of natural resources and the environment. This will keep the community in line with the situation and lead to appropriate alternatives. 3) There should be a clear and continuous process for working with the community, make communities understand their potential, and community resources. It can be used to guide the creation of a participatory process in sustainable resource management, and support to raise the level of knowledge of the community. 4) There should be empowerment to strengthen the youth to inherit and develop communities for more powerful management

\subsection{Academic Suggestion}

Issues related to the management of natural resources and the environment; studies have shown that land ownership rights have been increasingly changed to outsiders. When the villagers have no land, that is a fundamental factor in the agricultural production system there will be a process or phenomenon that affects their way of life, how to manage natural resources and environment and in terms of knowledge, How should the community develop knowledge to become a learning resource or a source of local wisdom that can manage natural resources and the environment effectively?

\section{Conclusion}

Ban Pasak Ngam is another community located in a vast forest area and rich in biodiversity. In the past era, production methods depend on the environment, natural resources, culture and beliefs. But nowadays it has changed with the flow of government development and interaction with outsiders, making the community way of life focus on production for the economy that satisfies outsiders thereby making use the resources in the forests. However, the community has only income as a factor for living and sustaining themselves, therefore, logging almost lost the value and meaning of cultural and natural resources. But under the community capital, the social relationship in the household is strengthened. Confidence in leadership as well as cultures, traditions and beliefs that have been passed down continuously to bring about adaptation, acceptance, support, reinforcement and participation in the learning process of leaders to drive the community to change for the better. From the change of natural resources in each time, it pointed out that under the situation of natural resource loss cause severe impacts on the ecosystems and livelihoods of the community, the actions of the community, together with people from outside the region, have been pressured by the government to suppress prevention. Forest resources and preserve forests to be maintained learning developed through the project due to the initiative gives communities an adaptation awareness and contribute together to revive the art of embroidery preserving natural resources for the better. The learning and adaptation process of the community are as follows: 1) lesson review, analyze and modify ways of thinking 2) Setting options and community planning 3) Wisdom and participation actions 4) Networking and learning power. As for the approach and mechanism for the integrated management of natural resources and environment, are as a result of the analysis on the strengths of the community in 
terms of natural resources and environment, Livelihoods, and community participation in all dimensions under the supervision of community leaders, who strictly adheres to the community rules for the successful operation to be achieved through the integration of all sectors. Also contributing to the management, maintenance and utilization of natural resources and the environment in the forest area of Ban Pa Sak Ngam community to be sustainably balanced.

\section{References}

Bureau of Evaluation And publish development Office of the Development Board Leading the National Economy and Society Evolution of Thai economic and social development. Bangkok: Srimuang Publication. 2013: page 4

Forest land Management office, Retrieved on 5 th January 2021, from http: //www.forest.go.th/land/forestmonitoring/

Natthawat Soonthonwaritthichod, A study of environmental problems in the district, three graduates: Factors affecting the development of natural resources and environment of the people of the Third District graduates (Research Report). Faculty of Humanities and Social Sciences, Phranakhon Si Ayutthaya Rajabhat University, 2013

Jermsak Pinthong, the evolution of the Bu Raise the arable land in the forest. Bangkok: Local Community Development Institute, 1992: 12-13.

Winit Pharcharuen, Participation of Villagers in the Conservation of Sustainable Watershed Restoration According to the Royal Initiative: A case study of Ban Pasak Ngam, Luang Nuea Sub-District, Doi Saket District Chiangmai Province, Dhammathas Academic Journal, Vol. 20 No. 2 (April-June 2020) pp 113-126. (in Thai)

Kanit Thanu Thamcharoen, Huai Hong Krai Royal Development Study Center As a result of royal initiatives A model for success in watershed management for Sustainable Development, Chiang Mai: Huai Hong Krai Development Study Center. As a result of the royal initiative, 2006

Phongphit, S., Folk Wisdom with Rural Development. Bangkok: Amarin Printing Group. 1993 p. 567 (in Thai)

Ponrach, P. A Book Review in "Ordained Forest, Destiny River, Forest and Water Cultural Management". Journal of Environmental Management,Vol. 9 No. 1, 2013. pp. 107-123. (in Thai) 